\title{
¡ㄱㅌㄷI\&NE
}

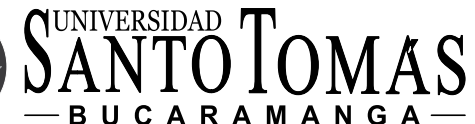

Revista ITECKNE - Universidad Santo Tomás, Seccional de Bucaramanga, Colombia, Vol. 18 № 1 enero - junio de 2021

\section{Experimental study on properties of mechanical resistance of polyamide in clay soil}

\section{Estudio experimental sobre propiedades de resistencia de la poliamida en suelos arcillosos}

\author{
Sivapriya S.V.' ${ }^{10}$; Gokul Krishnan J.2; Bijivemula Sruthi Reddy ${ }^{3}$; Roshan R. ${ }^{4}$; Syed Mohammed ${ }^{5}$ \\ 'Sri Sivasubramaniya Nadar College of Engineering, Chennai; sivapriyavijay@gmail.com \\ ${ }^{2}$ Sri Sivasubramaniya Nadar College of Engineering, Chennai; jgkrishna1@gmail.com \\ ${ }^{3}$ Sri Sivasubramaniya Nadar College of Engineering, Chennai; sruthireddyb99@gmail.com \\ ${ }^{4}$ Sri Sivasubramaniya Nadar College of Engineering, Chennai; roshan_davinci@yahoo.in \\ ${ }^{5}$ Sri Sivasubramaniya Nadar College of Engineering, Chennai; syed054@civil.ssn.edu.in
}

Recibido: 14 de octubre de 2020. Aceptado: 14 de diciembre de 2020

\begin{abstract}
The presence of clay soil causes problems at the base of the structure: it swells when wet and shrinks when dry, which provides a reduction in the resistance to cutting of the soil. Plastic waste in the form of polyamide powder (PA-12) from the 3D printing industry can be used to improve the mechanical properties of the soil. This experimental study is an attempt to combine these two objectives of stabilizing the soil by using waste PA12. The mechanical and shear resistant properties gave us confidence in choosing PA-12 as a stabilizer in clay soils, making them composite soils.
\end{abstract}

Keywords- Ground improvement; Expansive soil; PA12; Atterberg's limit; Unconfined compressive strength; Durability

Resumen- La presencia de suelo arcilloso causa problemas a la base de la estructura: se hincha cuando está mojado y se encoge en estado seco, lo que proporciona una reducción de la resistencia al corte del suelo. Los residuos plásticos en forma de poliamida en polvo (PA-12) de la industria de la impresión 3D se pueden utilizar para mejorar las propiedades mecánicas del suelo. Este estudio experimental es un intento de combinar estos dos objetivos de estabilizar el suelo mediante la utilización de desechos de PA-12. Las propiedades mecánicas y resistentes al cizallamiento dieron confianza al elegir PA-12 como estabilizador en suelos arcillosos, convirtiéndolos en suelos compuestos.

Palabras clave- Mejora del suelo; suelo expansivo; PA-12; límite de Atterberg; resistencia a la compresión no confinada; durabilidad

\section{INTRODUCTION}

Problematic soils refer to soils that expand (swell) or contract or settle to such an extent that the strength of the soil is not uniform. As soil provides the base for foundations and withstands the load, it must have proper bearing capacity. There can be a large risk involved if proper analysis is not done and this affects the behavior of the soil characteristics.

Black cotton soil, which is an example of expansive soil, generally refers to any soil or rock material that has high activity and potential for shrinking or swelling under changing moisture conditions. Black cotton soil deposits are generally present in the semi-arid regions of tropical and temperate climatic zones and are abundant where the annual evaporation exceeds the average precipitation[1]. Due to the presence of montmorillonite, severe damages in structures are bound to occur. Soil stabilization refers to the process of improving the overall bearing capacity, soil

Citar este artículo como: Sivapriya S.V, Gokul Krishnan J, Bijivemula Sruthi Reddy, Roshan R, Syed Mohammed. Experimental study on properties of mechanical resistance of polyamide in clay soil. ITECKNE, 18(1), 2021 pp. 39-45. DOI: https://doi.org/10.15332/iteckne.v18i1.2538 
strength, and durability characteristics under adverse moisture and stress conditions.

There is a huge scope in the field of environmental geotechnics particularly in soil stabilization and ground improvement. Through the use of certain chemical compounds and wastes which are normally unsafe for disposal, the twin benefits concerning sustainability and satisfying demands for the land is ascertained. Generally, solid wastes like fly ash, blast furnace slag, rice husk etc. are tried on such problematic soils as part of ground improvement techniques. When Sabat and Pradhan[2], Cokca [3], Oyekan et al.,[4], Muntohar and Hantoro[5] studied and tested the influence of various materials like rice husk ash, fly ash, polypropylene ash, cement kiln dust etc. in problematic expansive soils, several specific properties of the improved soil were respectively tested and studied. The importance of such properties and the choice of tests conducted to deduce an optimum proportion of the waste material depend mainly on the application intended and the material's adhesion with the soil. For example, Moses and Saminu [1] focused their work on the effect of cement kiln dust by conducting UCC, durability and CBR tests, bearing in mind how the modified soil deposits can be better ideated towards sub-base and base material applications in pavement [6]. Patel and Singh [7] carried out an study to investigate the suitability of randomly-distributed-glass, fiber-reinforced, cohesive soil as subgrade material. The effects of fiber content variation on compaction parameters of soil, soaking time variation (4-40 days) on CBR strength were investigated. It has been determined that CBR strength of soil has improved significantly with fiber content up to an optimum fiber content value of $0.75 \%$ and decreases with an increase in soaking time at any fiber content. It has been found out that glass fibre-reinforced soil can be extensively used as subgrade material.

Similarly, the study by Ramya and Jeyapriya [8] focused on the comparison of geopolymer soil column and untreated sand in the load-carrying capacity and settlement behavior of footings that were resting on loose sand. A load test was carried in a model footing resting on loose sand, with a geopolymer soil column and untreated sand at varying curing periods. It was then observed that a geopolymer soil column has a high bearing capacity compared to untreated sand, proving it to be an efficient technique for improving soil strength. The settlement was also reduced when using a geopolymer soil column.

The use of crumb rubber from tire waste, generated from automobile industry attracted researchers. The re-use of rubber has gained large importance to the geotechnical field, where the rubber waste (crumb rubber) has been fused with clayey soils and yielded desired results through the improvement of soil's strength parameters, namely the unconfined compressive strength and CBR values [9]. Crumb rubber works well in inorganic soils [10] compared to high organic clay soil. An optimum percentage of $15 \%$ crumb rubber, when mixed with inorganic clay, improves the shear strength of the soil and also reduces the thickness of the pavement [11], [12].

Small concentrations of polymer added to soil has resulted in improved properties like increased water retention, shear strength, ability to support the structure and resistance against erosion. In a study on polymeric stabilization of soft clay soils, 2 polymers-polyvinyl alcohol and 1,2,3,4 butane tetracarboxylic acid were added to expansive clay in different proportions. On testing and comparing with pure clay, polymer-stabilized soils showed better compressive strengths and the strength increased with curing time. Also, the polymer-stabilized clay soils showed better durability when soaked in water [13].

The domain of 3D printing affords a lot of scopes to utilize this technology more effectively. Many of the present manufacturing industries have begun to embrace this field for their overall development and easier workflow. The applications of this technology include automobile, biotechnology, airplanes and product manufacturing. By performing rapid prototyping across various engineering and biology fields, 3D printing has become a pioneering technology to accomplish design and research conclusions [14].

The trends in the material used for printing show that around $65 \%$ of the printing is done using plastic materials. Technology like Fused Deposition Modelling, Multi Jet Fusion Technique (MJF) and Selective Laser Sintering (SLS) are cheap and common practices adopted in modeIling [15]. The most common waste material generated after MJF is Polyamide 12 (PA 12) or Nylon 12. Nylon 12 is a polymer and an engineering thermoplastic, strong but flexible material. Despite the rapid advancement of 3D printing technology, the question of how plastic waste shall be re-used is a domain to explore. To minimize carbon footprints and progress towards zero waste economy, the waste management issues on MJF and SLS techniques can help spread this study across various disciplines. Liu et.al. [16] observes that waste materials can be recycled back. Though there is the scope of recycling waste for printing use, there is additional second energy and resource consumption involved in the process. In the research and development industry of 3D Printing, there have been numerous research projects going around the world to utilize the plastic waste generated to usable 3D filaments.

In the field of geo-technical engineering, soil stabilization is the process of improving the engineering properties of natural soils which are regarded unsuitable for housing or other construction purposes. The major reason for resorting to soil stabilization is to improve the shear strength properties of the soil, either through cohesion or friction. This study involves the reuse of plastic waste generated in the MJF technique for the applications of soil stabilization of problematic soils. 


\section{MATERIAL USED}

\subsection{Properties of PA-12}

Both MJF and SLS techniques involve the polymer-based composite raw material called Polyamide-12 (PA-12) with polymeric formula of [-(CH2)11C(O)NH-]n for functional prototyping and volume applications. PA-12 is characterized as a strong thermoplastic fine powder exhibiting a dense and nearly-isotropic mechanical performance. The polymer properties include resistance to impact and abrasion, low water absorbency and generally ideal for safety and durability applications. Owing to its appealing potential of plastic waste management across various sectors, the investigation of this PA-12 material can be related to soil improvement through its striking low-water absorbency and wear resistance feature [17].

The literature on the use of PA-12 waste for geotechnical applications is very sparse since the technology is currently new-found. The tests conducted to analyze the PA-12 properties, and the basic soil stabilization technique procedures for any virgin material in the soil sample and the preliminary lab tests conducted initially to gather the properties of the polyamide wastes serve as the impediment for the research.

The specific gravity of the PA-12 waste material was conducted using the density bottle and the value was found to be 0.73 . To check the reactivity of the PA-12 material in soil conditions, a $\mathrm{pH}$ test was conducted and indicated a value around 7. The summary of the properties of PA-12 is shown in Table I.

Table I.

PROPERTIES OF PA-12

\begin{tabular}{|c|c|}
\hline Parameter & Value \\
\hline Specific Gravity & 0.73 \\
\hline Particle size distribution & $<75 \mu$ \\
\hline $\mathrm{pH}$ & 7 \\
\hline
\end{tabular}

Source: the authors.

\subsection{Properties of Virgin Soil}

To reuse and utilize PA-12 waste material for the stabilization of problematic soil, laboratory tests were conducted to check the individual behavior of expansive soil, extracted from Thaiyur Lake, Chennai, India. The index properties of the soil have been summarized in Table II.

\section{METHODOLOGY}

After ascertaining the basic properties of PA-12 and the virgin expansive soil, tests are conducted to obtain the index properties of the polymer-induced expansive soil in various proportions. By doing this, the behavior of the soil is preliminarily understood for varying proportions of the waste material. PA- 12 was added to this problematic soil without incorporating lime, a common activating agent to analyze its potency independently. Using Unconfined Compression Strength, the shear strength of the soil sample was estimated (as shown in Fig. 1 and 2). The test was conducted according to IS 2720 :1991 (Part 10) [23]. From the obtained stress-strain graph, unconfined compressive strength and cohesion of the sample were estimated. The composition of PA-12 where the cohesion of the soil is maximum was found to be the optimum PA-12 content. Also, the results of the initial modulus and secant modulus was ascertained based on the UCS tests conducted for various percentages of PA-12.

Further in this study, durability tests were conducted for the sample with the optimum PA-12 percentage by weight. The test conducted was done to understand the influence of wet-dry cycles on the strength of this modified composite soil. To do so, the curing period for these soil samples were initially derived by studying how the strength of the sample tends to vary with time. It was seen that for trials prepared for a different curing period of 0,7 and 14 days, the cohesive strength of the soil tends to go on a rising trend, Fig.3. Hence, 14 days was fixed as the curing period for the durability test to be conducted.

Table II.

PROPERTIES OF THE VIRGIN SOIL

\begin{tabular}{|c|c|c|c|c|}
\hline Parameter & IS Code used & \multicolumn{3}{|c|}{ Soil } \\
\hline Specific Gravity & IS 2720 : Part $3: 1992[18]$ & 2.7 & & \\
\hline Particle size distribution & IS 2720 : Part $4: 1985[18]$ & Sand - $2.5 \%$ & Silt $-27.2 \%$ & Clay $-70.3 \%$ \\
\hline Liquid limit (\%) & \multirow[t]{3}{*}{ IS 2720 : Part $5: 1985[18]$} & \multicolumn{3}{|l|}{69} \\
\hline Plastic limit (\%) & & \multicolumn{3}{|l|}{34.3} \\
\hline Shrinkage limit (\%) & & \multicolumn{3}{|l|}{15.88} \\
\hline Optimum Moisture Content (\%) & \multirow[t]{2}{*}{ IS 2720 : Part $9: 1992[18]$} & \multicolumn{3}{|l|}{28.1} \\
\hline Unit Weight $\left(\mathrm{kN} / \mathrm{m}^{3}\right)$ & & \multicolumn{3}{|l|}{13.4} \\
\hline Cohesive Strength (kPa) & IS 2720 : Part $10: 1992[18]$ & \multicolumn{3}{|l|}{20.11} \\
\hline Soil Classification & IS $1498: 1970[18]$ & \multicolumn{3}{|c|}{ CH (High Compressible Clay) } \\
\hline
\end{tabular}

Source: the authors. 
Fig. 1. SOIL SAMPLE PREPARED FOR UCS TESTING

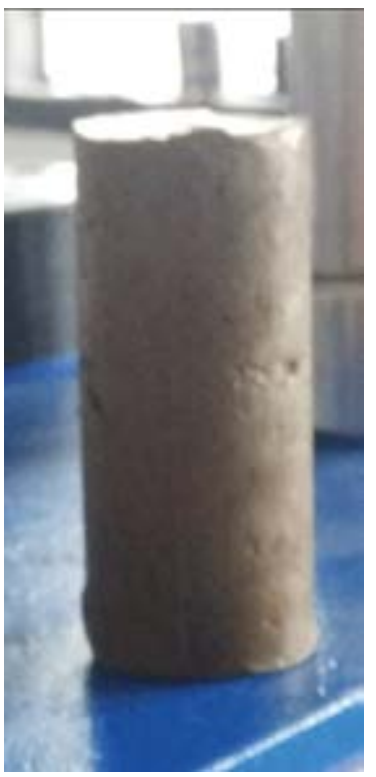

Source: the authors.

Fig. 2. SOIL SAMPLE DURING UCS TESTING

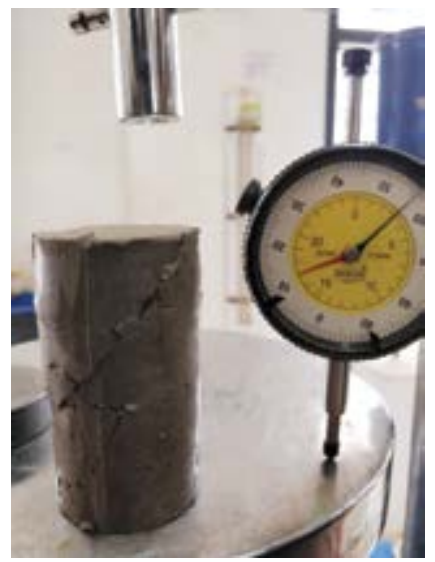

Source: the authors.

Fig. 3. GRAPH BETWEEN CURING PERIOD AND COHESIVE STRENGTH

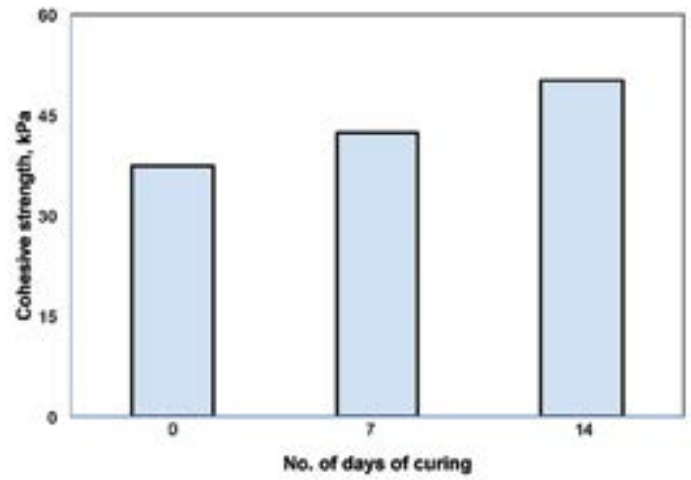

Source: the authors.
A set of 15 samples of soil with the optimum polymer content were prepared in UCS molds and were cured for 14 days (as shown in Fig. 4 and 5). Once the curing period had been completed, one of the cured samples were taken for testing without undergoing any wet-dry cycle. This is the strength of the modified sample after zero wet-dry cycles. The remaining samples were immersed in water for one day followed by drying them for another day. This is one complete cycle of wetting and drying. Thus, one wetdry cycle lasted 48 hours. Similarly, samples were tested for their strength characteristics till 3 cycles of wetting-drying. Therefore, the strength of the sample for the corresponding wet-dry cycles led to a comparative study between the initial clay and the polymer-modified problematic soil

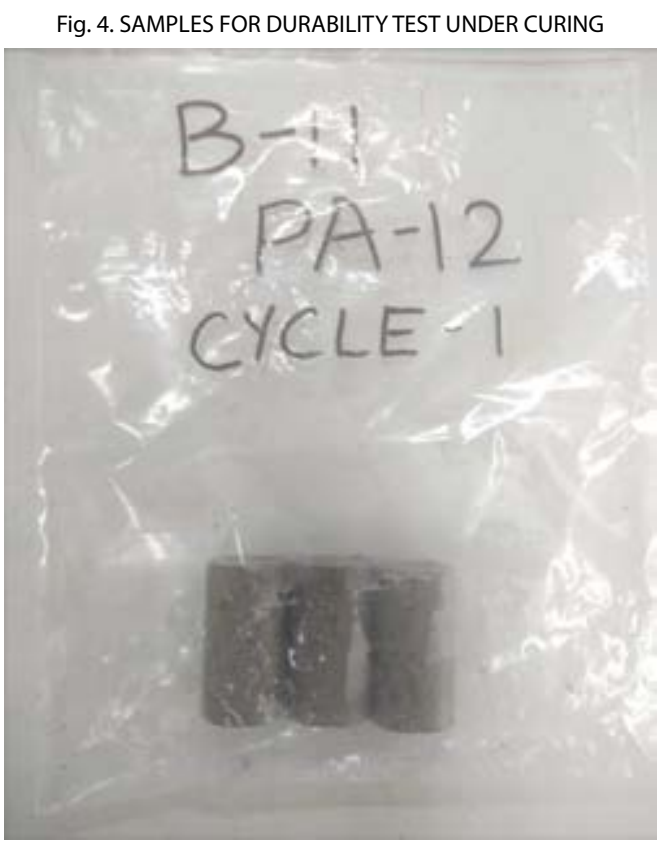

Source: the authors.

Fig. 5. SAMPLES FOR DURABILITY TEST UNDER WETTING AND DRYING CYCLES

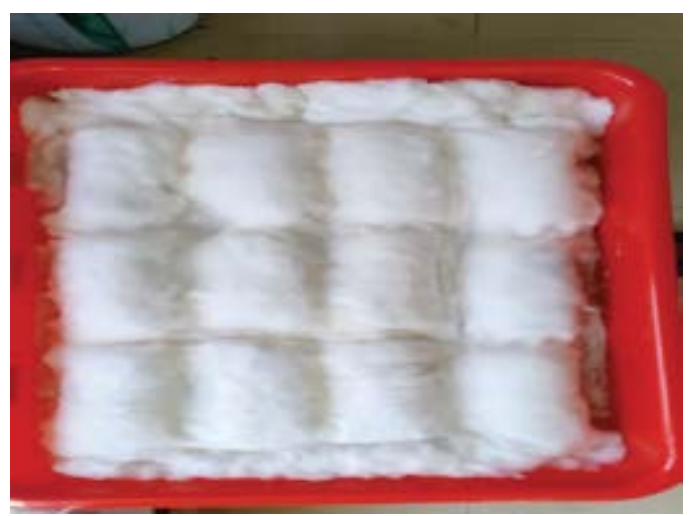

Source: the authors. 


\section{Results and Discussion}

\subsection{Index Properties of the Polymer-Induced Soil}

The index properties and behavior of polymer-induced soil (for varying proportions of PA-12) were understood by plotting the Atterberg line. In the figure 6, a decreasing pattern of liquid limit and plasticity index can be observed in the highly compressible clay region, with an increase in the percentage of PA-12 replacing the problematic soil. The reduction in the plasticity index implies that there was no change in the soil classification, which can be attributed to the non-reactive nature of PA-12.

Fig. 6. RELATION BETWEEN PLASTICITY INDEX AND LIQUID LIMIT FOR VARIOUS PERCENTAGES OF PA-12

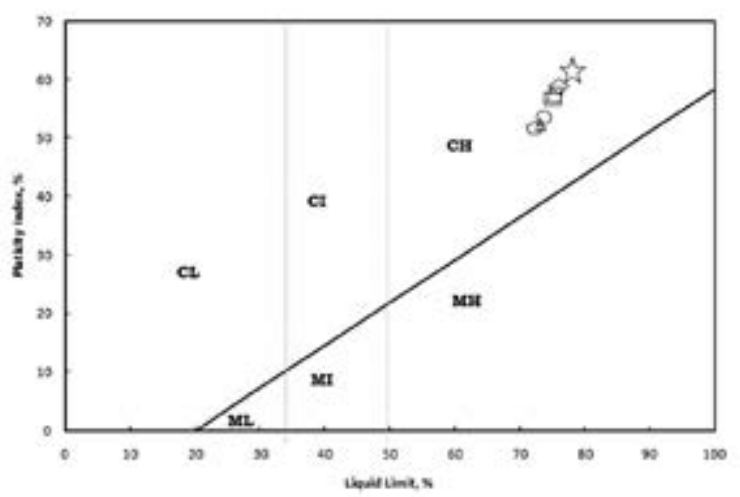

나 $0 \% \mathrm{PA}-12, \diamond 3 \% \mathrm{PA}-12, \square 4 \% \mathrm{PA}-12, \square 5 \% \mathrm{PA}-12$

$\bigcirc 6 \% \mathrm{PA}-12, \triangle 7 \% \mathrm{PA}-12, \triangle 8 \% \mathrm{PA}-12$

Source: the authors.

\subsection{Strength Properties of the Polymer-Induced soil}

The shear strength of the problematic soil is mainly attributed to its cohesion as the clay was of clayey nature. For improved shear strength properties for better applications, PA-12 waste material was added in varied proportions to the virgin soil. It can be seen that the addition of PA-12 yielded desirable results, with a steady increase in cohesion with increasing concentration of PA-12. Initially, samples were prepared with varying percentage, and it was observed that there was an increase in strength from $3 \%$ to $5 \%$ and subsequent decline when $10 \%$ was tested. Therefore, 3 samples from each of the percentages starting from 3 to 8 were prepared and a UCS test was conducted to understand how the shear strength varied. Figure 7, shows the comparative trend of how the strength properties varied with the percentage of PA-12 replaced in it.

It was observed that the value of unconfined compressive stress obtained based on load-deflection in the UCS test seems to be increasing from 3 to $6 \%$ of PA-12 replacing the problematic soil. However, the value seems to after addition of $7 \%$ and $8 \%$ PA-12. Based on the results shown in the graph, the optimum percentage of PA-12 in the problematic soil was found to be $6 \%$, Fig. 8 . The relation between the unconfined compressive strengths with varied percentages of PA-12 is given in fig 9. While comparing the percentage increase in shear strength of the soil with the replacement of PA -12, the maximum increase was observed as $86.26 \%$ of the optimum PA-12 percentage content when compared with the virgin soil, Fig. 9.

Fig. 7. GRAPH BETWEEN COHESIVE STRENGTH AND \% OF PA-12

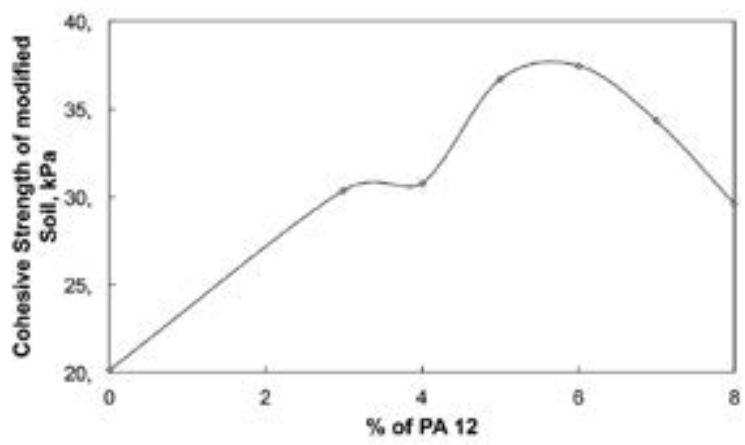

Source: the authors.

Fig. 8. STRESS-STRAIN GRAPH OF THE COMPOSITE SOIL WITH OPTIMUM PERCENTAGE OF PA-12

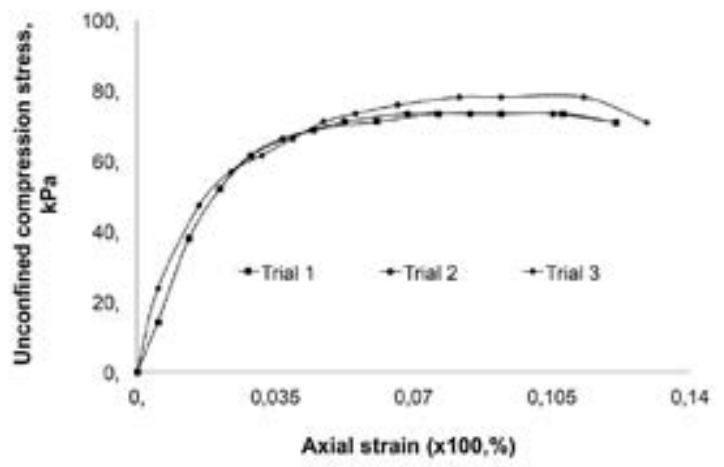

Source: the authors.

Fig. 9. GRAPH BETWEEN INCREASED COHESIVE STRENGTH AND PERCENTAGE OF PA-12

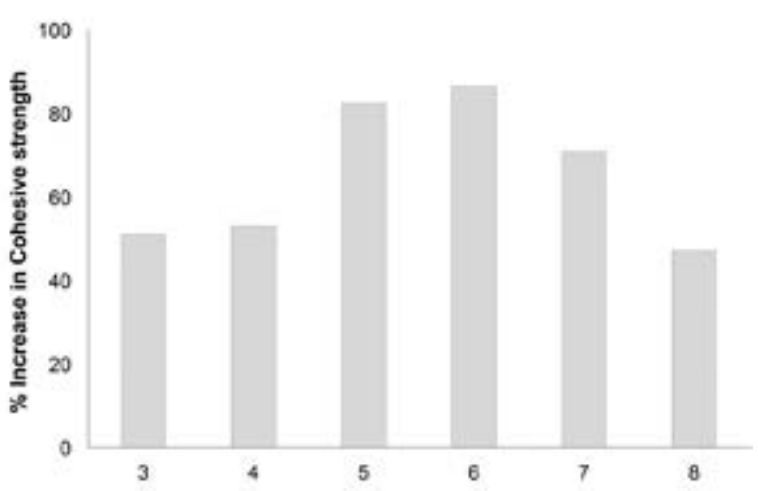

Source: the authors. 
Initial Modulus is defined as the slope of the tangent to any point in an inelastic region. It is used to study the behavior and pattern of initial settlement, which is derived from UCS tests. A tangent is drawn from the origin to touch a point on the curve, and the slope of this tangent is called the tangential modulus of the soil. The resistance to settlement is directly proportional to the tangential modulus of the soil, i.e. the steeper the tangent, the more stable that soil is. The results of the initial modulus of the soil for a varied percentage of PA-12 is shown in Table III. From figure 10 , the hardness of the material increases by 2.4 times the initial value. This clearly shows the better bond development between the polymer and the soil particles. With the further replacement of PA-12 in the soil, the modulus value reduced and went beyond the initial value; making $8 \%$ of PA-12 a less suitable proportion.

TABLE III.

INITIAL MODULUS FOR VARIED PERCENTAGES OF PA-12

\begin{tabular}{|c|c|c|}
\hline PA-12\% & $\begin{array}{c}\text { Initial Modulus } \\
(\mathbf{k P a})\end{array}$ & $\begin{array}{c}\text { Secant Modulus } \\
(\mathbf{k P a})\end{array}$ \\
\hline 0 & 1875 & 545 \\
\hline 3 & 2500 & 750 \\
\hline 4 & 3000 & 833.33 \\
\hline 5 & 3333 & 937.50 \\
\hline 6 & 4500 & 1666.67 \\
\hline 7 & 2632 & 1250 \\
\hline 8 & 1832 & 937 \\
\hline
\end{tabular}

Source: the authors.

Fig. 10. INFLUENCE OF PA-12 IN INITIAL MODULUS

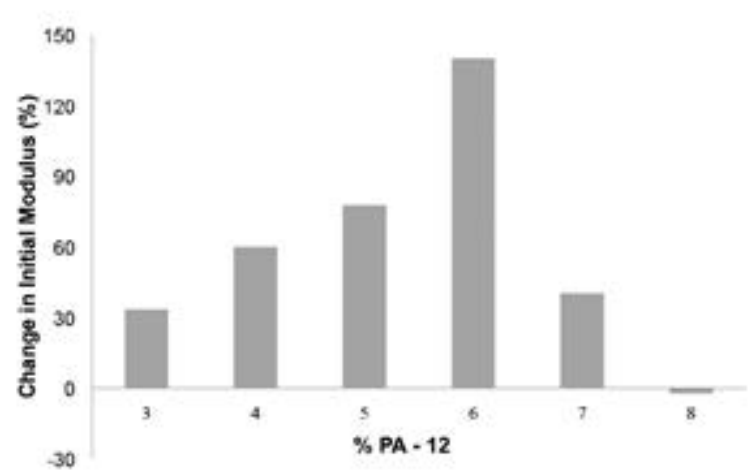

Source: the authors.

Secant Modulus is defined as the slope of the line joining any point in the inelastic region to the origin. It is used to analyze the stability of the soil concerning resistance to its settlement, by drawing a secant from the origin of the graph to the peak point of the curve. The greater the slope of the secant, the more stable the soil is. The secant moduli for various concentrations of PA-12 in the composite soil are listed in Table III. The secant modulus is generally represented as 0.7 - 0.8 times the initial tangent modulus. However, with the addition of polymer, it has reduced to
0.3 - 0.5 times the initial modulus of PA-12 added soil due to reduction in the inelastic region. It was also observed in Fig.11, that the reduction in the modulus after the peak value at $6 \%$ - $1666.67 \mathrm{kPa}$ did not go beyond the initial value for the proportions considered in the tests.

Fig. 11. INFLUENCE OF PA-12 IN SECANT MODULUS

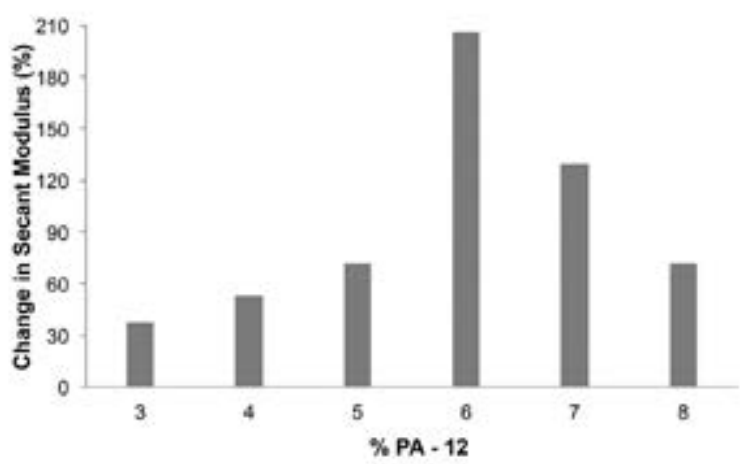

Source: the authors.

\subsection{Durability test results}

Keeping the optimum polymer concentration as the $6 \%$ ideal percentage of PA-12 replacing the soil, a durability test was conducted to analyze the strength performance of the polymer-stabilized soil under the influence of moisture conditions. The zeroth cycle (samples without wetting/ drying) were initially tested and found to have a higher value than the natural clay sample. Further, up to all the 3 cycles of wetting and drying, the UCS value progressively increased with each wet-dry cycle. By plotting the load-deflection co-ordinates for each of the samples in the respective percentages, we have positive trends in the strength and durability performance of the polymer-stabilized soil, as shown in Fig. 12. A considerably manifold increase in the strength can be observed after curing is done, indicating that PA-12 can be a potential stabilizer and can promise better results with curing.

From Figure 12, it can be observed that PA-12 has the capability of improving strength about 7 to 8 times the original cohesive strength of a problematic soil through physical stabilization. Even under the 3rd cycle, the strength shows a marginal declination compared to 2 nd cycle, indicating it is a viable stabilizer. Potentially, ground improvement through physical stabilization highly dependent on the particulate interaction which binds the soil particles by occupying the voids or by increasing the frictional strength through physical activity. PA-12, as its fine powder that can occupy the interstitial pore spaces, can have the good binding capability and result in high unconfined compressive strength of the soil. A varying percentage of PA-12, UCS tests were carried out repeatedly and we found $6 \%$ as an ideal percentage to produce better strength results. Additionally, the durability tests conducted also indicated the potential benefit of PA-12 for field practice. 
Fig. 12. GRAPH BETWEEN WET-DRY CYCLE AND COHESIVE STRENGTH

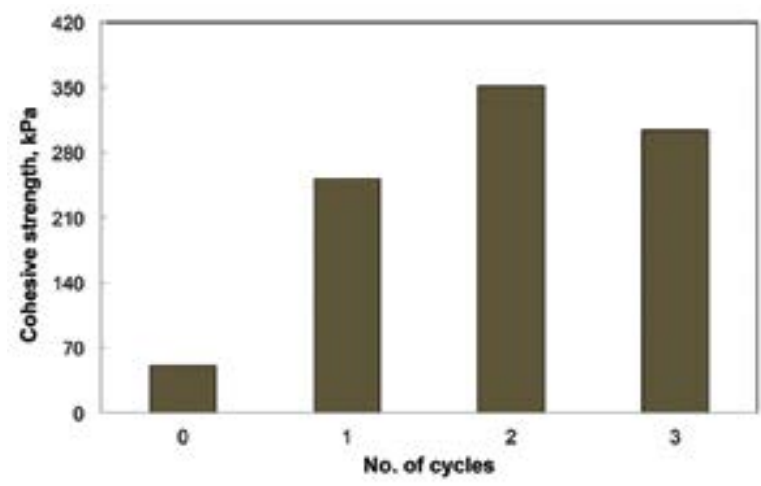

Source: the authors.

\section{CONCLUSION}

The behavior of the soil under varying percentage of PA-12 replacing the soil was laboratory-tested and studied. Different tests to derive its Atterberg limits, cohesive strength, initial and secant moduli and durability were conducted to arrive at an optimum percentage of PA-12 replacement in the soil and also understand the degree at which the stabilizing material is capable of modifying the problematic soil. The following conclusion were obtained:

1. The Plasticity Index (IP) decreased with an increment in the percentage of PA-12 leading to an increase the workability of the soil.

2. Wiith the addition of concentration of PA-12 in the problematic soil, there is a steady increase in cohesion.

3. The shear strength of the virgin soil is $20.11 \mathrm{kPa}$; with an increase of polyamide to $6 \%$, the shear strength increases to $86.28 \mathrm{kPa}$. The optimum percentage of PA-12 is thus found to be $6 \%$.

4. To understand the influence of durability of this composite soil, tests were conducted with a chosen curing period of 14 days. The samples were able to withstand 2 cycles of wetting and drying after the curing period. The durability of the sample showed a significant increase in shear strength after 2 cycles by showcasing an increase by 7 times when compared to 0 cycles for the optimum percentage of PA-12.

\section{REFERENCES}

[1] M. George and A. Saminu, Cement Kiln Dust Stabilization of Compacted Black Cotton Soil,Electron. J. Geotech. Eng.,vol 17, pp 825-836, 2012.

[2] A. K. Sabat and A. Pradhan, "Fiber reinforced, fly-ash-stabilized expansive soil mixes as subgrade material in flexible pavement," Electron. J. Geotech. Eng., vol. 19 T, pp. 5757-5770, 2014.

[3] Cokca Erdal, "Use of Class C Fly ashes for the Stabilization of an Expansive Soil," J. Geotech. Geoenvironmental
Eng., vol. 127(7), pp. 568-573, July 2001, DOI: https://doi.org/10.1061/(asce)1090-0241(2001)127:7(568)

[4] G.L. Oyekan, E.A. Meshida and A.O. Ogundalu, "Effect of ground polyvinyl waste on the strength characteristics of black cotton clay soil," J. Eng. Manuf. Technol., vol 1(1) pp. 1-10, june, 2013, DOI: 10.33500/jemt.2013.1.001

[5] A. S. Muntohar and G. Hantoro, "Influence of rice husk ash and lime on engineering properties clayey subgrade," Electron. J. Geotech. Eng., vol. 5, no. May, 2000.

[6] Akshay Kumar sabat and Subasis Pati, "A review of literature on stabilization of expansive soil using solid wastes," Electron. J. Geotech. Eng., vol. 19, pp. 6251-6267, 2014.

[7] Suchit Kumar Patel and Baleshwar Singh, "Investigation of glass fibre reinforcement effect on the CBR strength of Cohesive soil," in Ground Improvement Techniques and Geosynthetics, Lecture Notes in Civil Engineering, Springer Singapore, 2019, pp 85-94. DOI: https://doi.org/10.1007/978-981-13-0559-7_8

[8] M.S. Ramya and S.P. Jeyapriya, "Behaviourial study on geopolymer column in soil," in Indian Geotechnical Conference, Chenai, India, 2016.

[9] J.S. Yadav and S.K. Tiwari, "Evaluation of the strength characteristics of cement-stabilized clay - crumb rubber mixtures for its sustainable use in geotechnical applications," Environ. Dev. Sustain., vol 20, pp. 1961-1985, oct. 2018. DOI: https://doi.org/10.1007/s10668-017-9972-2

[10] S.V. Sivapriya and N. Charumathy, "Effect of crumb rubber on inorganic and high compressible clay," in Advances in Materials and Metallurgy. Lecture Notes in Mechanical Engineering. Springer, Singapore, 2018, pp. 67-73. DOI: https://doi.org/10.1007/978-981-13-1780-4_8

[11] S.V. Sivapriya, "Stress-strain and penetration characteristics of clay modified with crumb rubber," Rev. Fac. Ing., vol. 27(49), pp. 65-75, 2018, DOI: https://doi.org/10.19053/01211129.v28.n49.2018.8745

[12] S.V. Sivapriya, "Compaction Characteristics of Modified Clay Soils with Various Proportions of Crumb Rubber," in Sustainable Practices and Innovations in Civil Engineering. Lecture Notes in Civil Engineering, Springer, Singapore, 2020, pp. 183-190. DOI: https://doi.org/10.1007/978-981-15-5101-7_18

[13] M. Mirzababaei, A. Arulrajah and M. Ouston, "Polymers for stabilization of soft clay soils," in Procedia Engineering, Vol, 189, pp. 25-32, 2017. DOI: https://doi.org/10.1016/j.proeng.2017.05.005

[14] Kalnad Chandrashekhar, "A review on 3D Printing," Int. J. Adv. Res. Electron. Commun. Eng., vol. 5(7) pp. 2001-2004, july, 2016.

[15] Sculpteo, "The State of 3D Printing Report," Sculpteo, A brand $B A S F, 2020$. sculpteo.com.

[16] Z. Liu, Q. Jiang, Y. Zhang, T. Li and H. C. Zhang, "Sustainability of 3D printing: A critical review and recommendations," ASME 2016 11th Int. Manuf. Sci. Eng. Conf. MSEC 2016, Blacksburg, Virginia, USA. June 27-July 1, 2016. DOI: https://doi.org/10.1115/MSEC2016-8618

[17] Sam Taylor, "Waste Management Implications of 3D Printing," Apr. 16, 2019. Available: https://www.ecomena. org/3d-printing-waste-management/

[18] "Indian Standard. Methods of Test for Soils". Bureau of Indians Standards. 1981. Available: https://standardsbis.bsbedge. com/BIS_SearchStandard.aspx?keyword=\%20Methods $\% 20$ of $\% 20$ Test $\% 20$ for $\% 20$ Soils\&id $=0$ 